\title{
The Mössbauer Spectroscopy Studies of $\epsilon$ to Cementite Carbides Transformation during Isothermal Heating from As-Quenched State of High Carbon Tool Steel
}

\author{
P. BAŁA ${ }^{a, *}$, J. KRAWCZYK ${ }^{a}$ AND A. $\mathrm{HANC}^{b}$ \\ ${ }^{a}$ AGH University of Science and Technology \\ Faculty of Metals Engineering and Industrial Computer Science \\ al. Mickiewicza 30, PL-30-059 Kraków, Poland \\ ${ }^{b}$ Institute of Materials Science, Silesian University \\ Bankowa 12, 40-007 Katowice, Poland
}

\begin{abstract}
This work presents results of investigations using the Mössbauer spectroscopy technique and their interpretation concerning transformation of $\epsilon$ to cementite carbides during tempering in relation to the previously conducted dilatometric, microscopic and mechanical investigations. Investigations were performed on $120 \mathrm{MnCrMoV} 8-6-4-2$ steel. The influence of the tempering time on nucleation and solubility of $\epsilon$ carbides, and on cementite nucleation and growth, was determined. The analysis of phase transformations during various periods of tempering using the Mössbauer spectroscopy technique made possible to reveal fine details connected with the processes.
\end{abstract}

PACS numbers: 76.80.+y, 31.30.Gs, 75.50.Bb

\section{Introduction}

During heating from the quenched state (tempering) of unalloyed, medium and high carbon steels, three principal transformations can be observed: precipitation of $\epsilon\left(\mathrm{Fe}_{2.4} \mathrm{C}\right)$ carbide (hexagonal crystal structure), transformation of retained austenite into lower bainite (tempered martensite) and precipitation of cementite $\left(\mathrm{Fe}_{3} \mathrm{C}\right)$ with orthorhombic crystal structure. In steels containing alloying elements causing an effect of secondary hardening (V, Mo, W), a fourth transformation

*corresponding author; e-mail: pbala@agh.edu.pl 
occurs: precipitation of $\mathrm{MC}$ carbides with fcc crystal structure and $\mathrm{M}_{2} \mathrm{C}$ carbides with hexagonal crystal structure, that nucleate independently [1-10].

Application of dilatometric, magnetic, X-ray, and microscopic analysis gives a lot of useful information about kinetics of the phase transformations during tempering [1-10], especially about carbides precipitation, transformations and growth. Many works [11-18] showed that the Mössbauer spectroscopy gives a possibility to obtain new data, which may help more detailed interpretation of the phenomena connected with phase transformations during tempering.

This work presents the results of investigations using the Mössbauer spectroscopy technique and their interpretation concerning transformation of $\epsilon$ to cementite carbides during isothermal heating from as-quenched state in relation to previously conducted dilatometric and microscopic investigations [1-3].

The aim of this work is to determine the $\epsilon$ to cementite transformations occurring during isothermal heating after quenching of a high carbon alloy steel and its effect on the development of steel microstructure.

\section{Test material}

Investigations were performed on 120MnCrMoV8-6-4-2 steel, which was designed in 1998 in Phase Transformations Research Group of Department of Physical and Powder Metallurgy at the Faculty of Metals Engineering and Industrial Computer Science at AGH University of Science and Technology in Kraków. Table lists the chemical composition of the tested steel.

\section{TABLE}

Chemical composition of the investigated steel [mass \%].

\begin{tabular}{c|c|c|c|c|c|c|c|c}
\hline \hline $\mathrm{C}$ & $\mathrm{Mn}$ & $\mathrm{Si}$ & $\mathrm{P}$ & $\mathrm{S}$ & $\mathrm{Cr}$ & $\mathrm{Mo}$ & $\mathrm{V}$ & $\mathrm{Al}$ \\
\hline 1.22 & 1.93 & 0.19 & 0.018 & 0.02 & 1.52 & 0.36 & 0.17 & 0.04
\end{tabular}

A $50 \mathrm{~kg}$ ingot (120 mm diameter), produced in laboratory conditions, was forged into bars with a cross-section of $20 \times 35 \mathrm{~mm}$. The bars were then fully annealed and the samples for further investigations were cut off from these bars.

Austenitizing temperature $\left(900^{\circ} \mathrm{C}\right)$ - heating temperature for hardening was determined from experimentally performed series of hardening treatments. The critical temperatures (temperatures of phase transformations from $\mathrm{Fe}-\mathrm{C}$ phase diagram, used in heat treatment) for the investigated steel are: $\mathrm{A}_{\mathrm{C} 1 \mathrm{~s}}=730^{\circ} \mathrm{C}$, $\mathrm{A}_{\mathrm{C} 1 \mathrm{f}}=750^{\circ} \mathrm{C}$.

\section{Experimental details}

Samples taken from investigated steel were austenitized at the temperature of $900^{\circ} \mathrm{C}$ and hardened in oil. Austenitizing time was $20 \mathrm{~min}$. Then seven of eight samples were tempered. Tempering consisted of holding the samples at 
$200^{\circ} \mathrm{C}$ for defined periods. All the times mentioned above were selected basing on IHT (isothermal heating transformations during tempering) diagram presented in work [2].

Sample No. 1 was left in as-quenched state. After hardening, samples were heated up to $200^{\circ}$ C. Sample No. 2 was heated for 0.5 h, sample No. 3 was heated for 1.0 h, sample No. 4 was heated for 1.5 h, sample No. 5 was heated for $2 \mathrm{~h}$, sample No. 6 was heated for $3 \mathrm{~h}$, sample, sample No. 7 was heated for $8 \mathrm{~h}$ and sample No. 8 was heated for $24 \mathrm{~h}$. All samples were ground (about $1 \mathrm{~mm}$ ) and polished.

For the study, conversion electron Mössbauer spectroscopy (CEMS) with gas detector, filled with $98 \% \mathrm{He}+2 \% \mathrm{Ar}$, under pressure of $0.9 \mathrm{~atm}$ was applied. The Mössbauer source consisted of ${ }^{57} \mathrm{CoRh}$ with activity of $10 \mathrm{mCi}$. Application of CEMS technique allowed to investigate the surface layers of thickness of about $100 \mathrm{~nm}$.

\section{Results and discussion}

Basing on the analysis of hyperfine magnetic field and on previously performed investigations [1, 2], conducted with different techniques, it is possible to determine which phase a particular spectrum comes from. The analysis of hyperfine magnetic field (the Zeeman sextets) allowed to distinguish between component spectra coming from ${ }^{57} \mathrm{Fe}$ atoms located in the structure of martensite, in the structure of $\epsilon$ carbide, and in cementite, independently precipitated during tempering. Also another component spectrum was identified, characterized by a single peak (without quadrupole splitting of the Zeeman sextet) as corresponding to precipitations of alloyed hypereutectoid cementite, undissolved during austenitizing. This cementite is paramagnetic, which results from high concentration alloy elements such as $\mathrm{Cr}$ and $\mathrm{Mn}[2,3]$.

The obtained Mössbauer spectra were presented in Fig. 1. In the figures, component spectra make the basis for a description of the individual structural components and their changes in time.

On the account of a possibility of using the data from [11-18], concerning the value of the hyperfine field on ${ }^{57} \mathrm{Fe}$ nuclei, located in various ferromagnetic phases or in chemical compounds occurring in the steels, the easiest way was to attribute the individual components of the experimental Mössbauer spectra to phases and chemical compounds occurring in the microstructure of the tempered steel. Figure 2 presents changes in hyperfine magnetic field $(H)$ for a component corresponding with iron carbides vs. tempering time. As one could see, already in the sample tempered for $0.5 \mathrm{~h}, \epsilon$ carbides precipitated from the martensitic matrix. The value of measured hyperfine magnetic field $(\approx 243 \mathrm{kG})$ is slightly higher than the ones reported in the literature $(230 \div 240 \mathrm{kG})$ [15]. It is most probably caused by a high participation of interphase boundaries $\epsilon$ - martensitic matrix, because the process of carbides has 


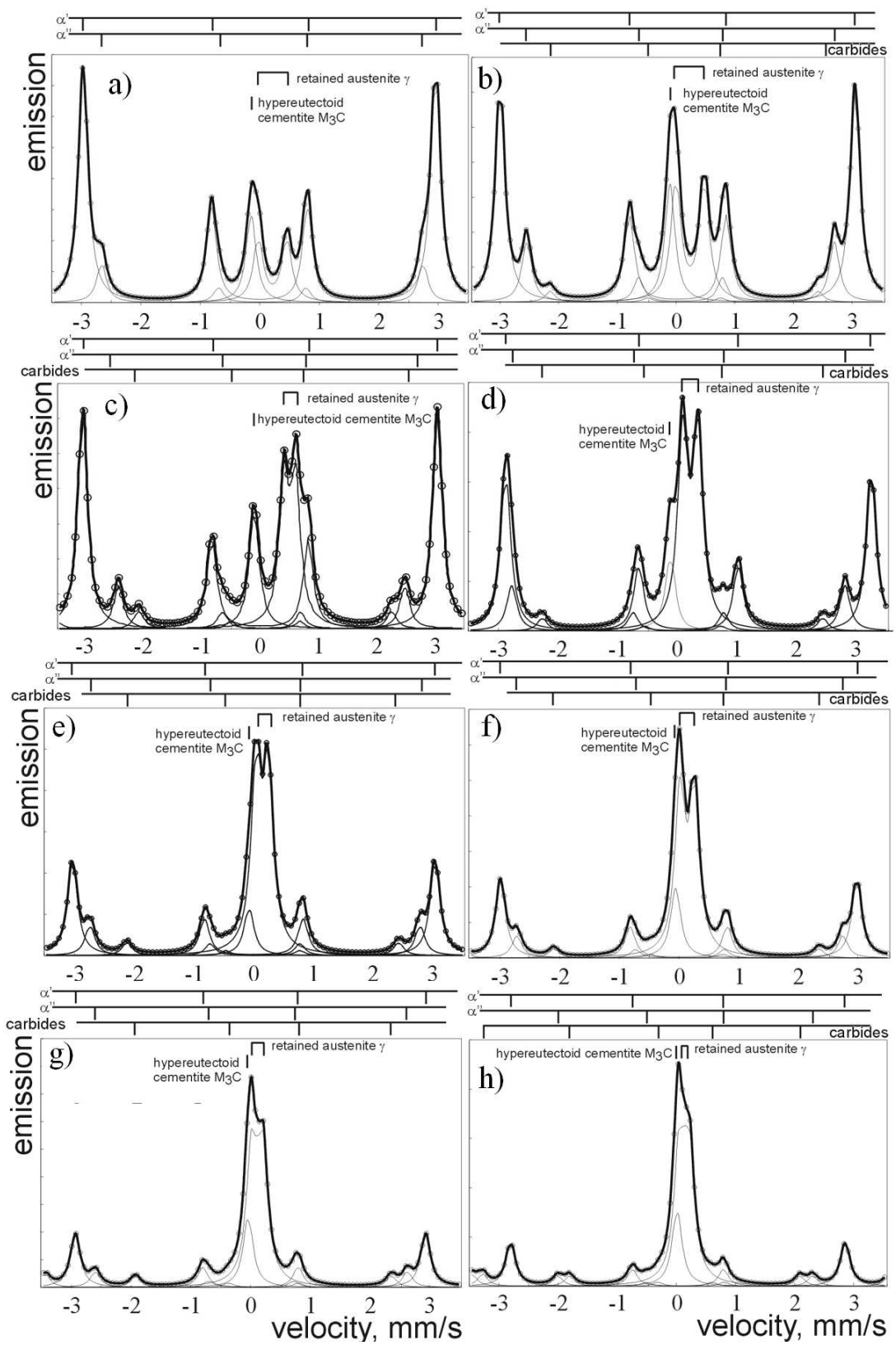

Fig. 1. Middle part of obtained Mössbauer spectra: (a) in as-quenched state, (b) after tempering at $200^{\circ} \mathrm{C}$ for $0.5 \mathrm{~h}$, (c) after tempering at $200^{\circ} \mathrm{C}$ for $1 \mathrm{~h},(\mathrm{~d})$ after tempering at $200^{\circ} \mathrm{C}$ for $1.5 \mathrm{~h}$, (e) after tempering at $200^{\circ} \mathrm{C}$ for $2 \mathrm{~h}$, (f) after tempering at $200^{\circ} \mathrm{C}$ for $3 \mathrm{~h},(\mathrm{~g})$ after tempering at $200^{\circ} \mathrm{C}$ for $8 \mathrm{~h}$, and (h) after tempering at $200^{\circ} \mathrm{C}$ for $24 \mathrm{~h}$. $\alpha^{\prime}-\mathrm{Fe}$ atoms from bcc matrix, which do not have $\mathrm{C}$ atoms in their neighborhood, $\alpha^{\prime \prime}$ - Fe atoms from bcc matrix, which have $\mathrm{C}$ atoms in their neighborhood. 


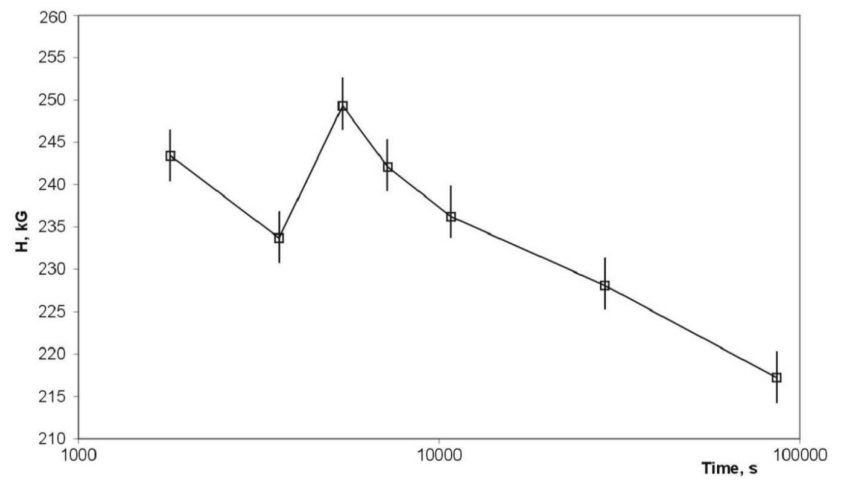

Fig. 2. Changes of hyperfine magnetic field $(H)$ of component Mössbauer spectrum coming from iron carbides precipitated from martensitic matrix.

been only initiated. That is why the share of ${ }^{57} \mathrm{Fe}$ atoms located at interphase boundaries is significant. After $1 \mathrm{~h}$ tempering, the value of the hyperfine magnetic field connected with $\epsilon$ carbides was $\approx 233 \mathrm{kG}$. This effect results most probably from an increase in $\epsilon$ carbides precipitation, and a decrease in the share of iron atoms at phase boundaries between $\epsilon$ carbides and the martensitic matrix. Elongation of tempering time to $1.5 \mathrm{~h}$ caused a repeated increase in hyperfine magnetic field for this component. The increase should be connected with the start of cementite precipitation, with a possible slight change in $\epsilon$ carbides chemical composition or possibly with the start of their dissolution. The value of the hyperfine magnetic field measured after some time is a complex one connected with $\epsilon$ carbides and precipitating cementite $(230 \div 170 \mathrm{kG})$. Further elongation of the tempering time causes a decrease in hyperfine magnetic field, resulting from dissolution of $\epsilon$ carbides accompanied by cementite precipitation. The paper [2] states that during continuous tempering from the hardened state, cementite nucleates independently of strips boundaries and of martensite twin roots, drawing carbon from the retained austenite. This causes a destabilization of austenite and its transformation into lower bainite (tempered martensite). Analysing the Mössbauer spectra (see Fig. 1), one may ascertain that when the tempering time increases, quantity of the retained austenite in the structure of the investigated steel also increases (the component depicted as a double line quadrupole splitting). Presence of the retained austenite and possible effects of its transformation cannot be omitted while considering the $\epsilon$ - cementite transformation. It is an apparent increase connected with a higher stability of the retained austenite tempered for a longer time. Such austenite transforms more hardly during grinding the samples for these investigations. Basing on the obtained experimental results, it may be ascertained that it is most probably a result of dissolution of $\epsilon$ carbides in the martensitic matrix, leading to an increase in carbon concentration in martensite, which decreases the propelling force of carbon diffusion from the austenite towards 


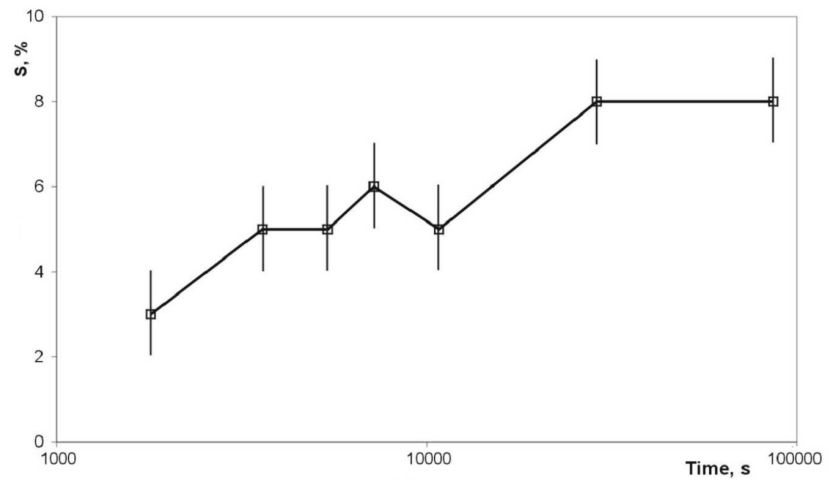

Fig. 3. Changes of intensity $(S)$ of component Mössbauer spectrum coming from iron carbides precipitated from martensitic matrix.

austenite-martensite boundaries. As a consequence, the process of cementite precipitation has slowed down, and the austenite stability has increased.

In Fig. 3, changes in intensity of the component connected with the presence of iron carbides precipitating from the matrix vs. tempering time are shown. As one can see, an elongation of the $200^{\circ} \mathrm{C}$ tempering time from 0.5 to $1 \mathrm{~h}$ leads to an increase in $\epsilon$ carbides share in the structure of steel. After $1.5 \mathrm{~h}$ tempering, the increase in carbides contents has not been ascertained, which may confirm the fact that most probably after this time the process of $\epsilon$ carbides dissolution and cementite precipitation has started. As a consequence, the total share of iron carbides precipitated from the martensitic matrix has not changed. However, the result may indicate that after $1 \mathrm{~h}$ tempering the process of $\epsilon$ carbides precipitation has ended, and after $1.5 \mathrm{~h}$ they are stable. But a disturbance of the hyperfine magnetic field measured in the sample after $1.5 \mathrm{~h}$ tempering (compare with Fig. 2) should be connected with a change in alloying of the $\epsilon$ carbides, and this seems improbable considering the low temperature of tempering.

An elongation of the tempering time to $2 \mathrm{~h}$ causes an increase in share of iron carbides precipitated from the martensitic matrix in the structure of the investigated steel. A decrease in the share of these carbides after $3 \mathrm{~h}$ should be explained by progress of $\epsilon$ carbides dissolution with small number and slow increase in cementite precipitations. This fact proves that cementite nucleates independently. If the cementite had nucleated on $\epsilon$ carbides, the total share of iron carbides could at the most remain the same. Therefore dissolution of $\epsilon$ carbides and cementite nucleation are two separate processes, however cementite nucleation depends on dissolution of $\epsilon$ carbides and on stability of retained austenite [2]. Further elongation of tempering time boosts the share of cementite at the cost of $\epsilon$ carbides. However, it is noteworthy that after $8 \mathrm{~h}$ and $24 \mathrm{~h}$ tempering, the same share of iron carbides precipitated from the martensitic matrix has been ascertained. This confirms the aforementioned proposition that dissolution of $\epsilon$ 


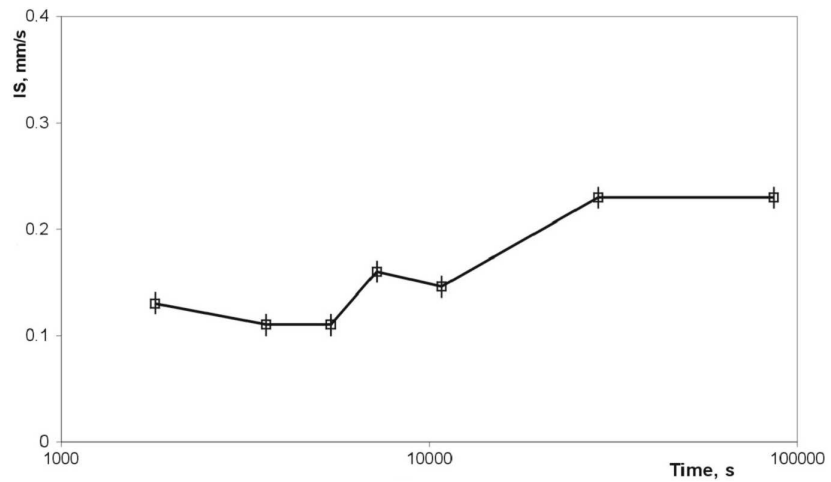

Fig. 4. Changes of isomeric shift (IS) of component Mössbauer spectrum coming from iron carbides precipitated from martensitic matrix.

carbides has caused a stability of retained austenite, leading to a halt in the process of cementite precipitation.

Figure 4 shows the differences in isomeric shift (IS) measured for components connected with carbides separated from the martensitic matrix vs. time of tempering of the investigated steel's samples at the temperature of $200^{\circ} \mathrm{C}$. The changes in IS values may indicate changes of the stresses in the matrix or at the phase boundary. Analyzing the changes of IS values vs. tempering time, it has been ascertained that after the initial stage (after $0.5 \mathrm{~h}$ ), when the process of $\epsilon$ carbides precipitation has been started, an increase in the share and precipitation scale of the $\epsilon$ carbides leads to a decrease in stresses because of a decrease in supersaturation of the martensitic matrix with carbon. The increase in IS value measured for the sample tempered for $2 \mathrm{~h}$ indicates that $\epsilon$ carbides has partially dissolved, leading to a re-increase in carbon contents in the matrix and to an increase in stresses in the martensite lattice. This increase may be caused by the precipitating cementite (an increase in share of ${ }^{57} \mathrm{Fe}$ atoms located in the cementite structure, having higher and higher share in the component connected with the analyzed carbides) or - what is most probable - by both these processes at the same time. A decrease in IS value, observed after $3 \mathrm{~h}$ tempering, results most probably from the precipitating cementite, leading to a decrease in carbon concentration in the proximity of these precipitates and a consequent decrease in stresses. Also a slowing down of $\epsilon$ carbides dissolution is probable, because the diffusion length would have been longer in order to equalize carbon concentration in martensite. The increase in IS after $8 \mathrm{~h}$ tempering should be connected with an increase in number of cementite precipitates, leading to an increase in stresses at the cementite-martensite boundary. As the stresses increased, carbon concentration in martensite did not decrease, and they might even increase owing to dissolution of $\epsilon$ carbides. This proves the fact that cementite draws carbon from the retained austenite. 
Changes in values of quadrupole splitting (QS) depending on tempering time of the investigated steel at $200^{\circ} \mathrm{C}$ are presented in Fig. 5. In a case of small particles of carbides precipitations (large value of grain boundaries) quadrupole splitting is giving on a level $0.1 \mathrm{~mm} / \mathrm{s}$ [15]. If carbides precipitations are large, QS is going down $[19,20]$. It is shown that QS has close values for samples tempered for $0.5 \div 1.5 \mathrm{~h}$. Decrease in QS value after $2 \mathrm{~h}$ tempering is most probably connected with the fact that at the first stage, small precipitations of $\epsilon$ carbides are dissolved, and as a consequence the larger ones having greater symmetry remained in the microstructure. Next increase in QS value after $3 \mathrm{~h}$ is caused by large quantity of small precipitations of cementite. A decrease in QS value, observed after 8 and $24 \mathrm{~h}$ tempering evidences an increase in cementite precipitations and in lattice symmetry (decrease in value of phase boundaries). These results correspond to work [14].

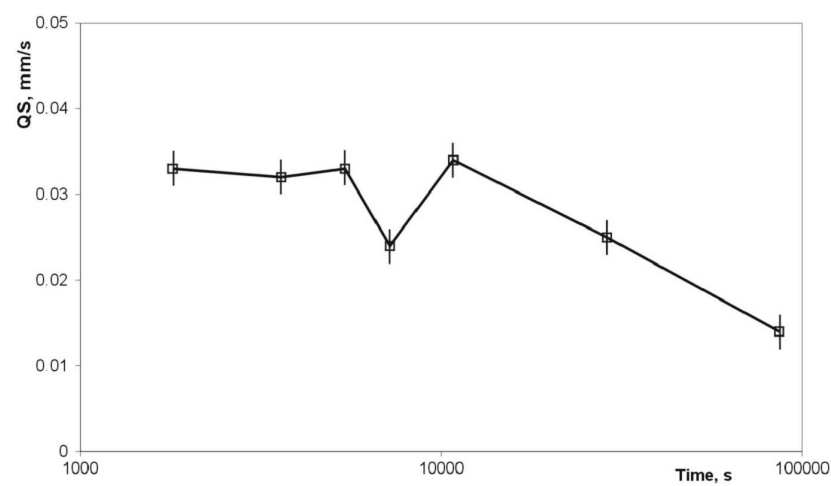

Fig. 5. Changes of quadrupole splitting (QS) of component Mössbauer spectrum coming from iron carbides precipitated from martensitic matrix.

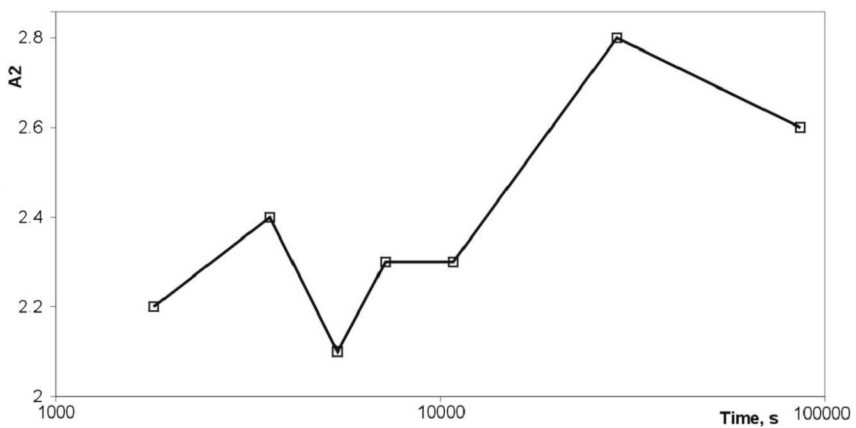

Fig. 6. Changes of A2 value of component Mössbauer spectrum coming from iron carbides precipitated from martensitic matrix.

Analysis of the A2 parameter - intensity ratio of component lines No. 2 to 3 in the Zeeman spectra - may indicate texture changes. Changes in A2 
parameter value for carbides separated from the martensitic matrix vs. tempering time at $200^{\circ} \mathrm{C}$ are shown in Fig. 6. As one can see, a lower $\mathrm{A} 2$ value for the sample tempered for $0.5 \mathrm{~h}$ than for the one tempered for $1 \mathrm{~h}$ confirms the fact that after $0.5 \mathrm{~h}$ the process of $\epsilon$ carbides precipitation has only started. As far as it is known [1-5], $\epsilon$ carbides nucleate on dislocations in several possible crystallographic dependences on the martensitic matrix, which in the steel is characterized by a certain texturing. That is why the increase in A2 value after $1 \mathrm{~h}$ indicates a larger number of these precipitations, whereas a decrease in A2 value after $1.5 \mathrm{~h}$ confirms the start of $\epsilon$ carbides dissolution and cementite precipitation. The cementite, nucleating at strip boundaries and martensite twin roots does not exhibit a precise crystallographic dependence on the martensitic matrix. Not before the extension of tempering time to $2 \mathrm{~h}$ it has been shown that cementite grows in a crystallographic dependence on the martensitic matrix, which is indicated by an increase in A2 value up to tempering time of $8 \mathrm{~h}$. A decrease in A2 value after $24 \mathrm{~h}$ tempering indicates that further increase in cementite precipitations does not depend on the martensitic matrix.

\section{Conclusions}

The obtained results lead to the following conclusions:

1. Using the Mössbauer spectroscopy, processes occurring during isothermal tempering of high-carbon alloy steel are described.

2. Independent cementite nucleation has been ascertained, i.e. $\epsilon$ carbides are dissolving in the martensitic matrix, and cementite is nucleating independently.

3. As a result of $\epsilon$ carbides dissolution in the martensitic matrix, carbon concentration in martensite increases, leading to a decrease in propelling force of diffusion of carbon from austenite onto austenite-martensite boundaries. This phenomenon in turn slows down the process of cementite precipitation, as well as increases the austenite stability.

4. Basing on changes in A2 values, it has been ascertained that both nucleation and growth of $\epsilon$ carbides take place in a precisely defined crystallographic dependence on the martensitic matrix.

5. Cementite nucleation is not oriented, and only its growth is oriented in relation to the martensitic matrix.

6. Optimum tempering time of tools made from the investigated steel should be in the range of $1.5 \div 2 \mathrm{~h}$.

\section{Acknowledgments}

The work was supported by the State Committee for Scientific Research, grant no. PB-581/T/2006. 


\section{References}

[1] P. Bała, J. Pacyna, J. Krawczyk, Archiv. Metall. Mater. 52, 113 (2007).

[2] P. Bała, Ph.D. Thesis, AGH University of Science and Technology, Kraków 2007, p. 42 .

[3] J. Krawczyk, P. Bała, J. Frạckowiak, Archiv. Mater. Sci. Eng. 28, 633 (2007).

[4] S. Murphy, J.A. Whiteman, Metall. Transact. 1, 843 (1970).

[5] R.C. Thomson, M.K. Miller, Acta Metall. 46, 2203 (1998).

[6] A.D.B. Gingell, H.K.D.H. Bhadeshia, D.G. Jones, K.J.A. Mawella, J. Mater. Sci. 32, 4815 (1997).

[7] R.W.K. Honeycombe, H.K.D.H. Bhadeshia, Steels. Microstructure and Properties, 2nd ed., Edward Arnold, London 1995.

[8] A.K. Sinha, Physical Metallurgy Handbook, McGraw-Hill, New York 2003.

[9] R. Padmanabhan, W.E. Wood, Mater. Sci. Eng. 65, 289 (1984).

[10] G. Krauss, Steels: Processing, Structure and Performance, ASM Int., Materials Park, Ohio 2005

[11] S.-J. Kown, S.J. Oh, J.H. Kim, S. Kim, S. Lee, Scr. Mater. 40, 131 (1999).

[12] V.G. Gavriljuk, Mater. Sci. Eng. A 345, 81 (2003).

[13] R. Ilola, V. Nadutov, M. Valo, H. Hänninen, J. Nucl. Mater. 302, 185 (2002).

[14] V.A. Shabashov, A.G. Mukoseev, V.V. Sagaradze, Mater. Sci. Eng. A 307, 91 (2001).

[15] V.A. Shabashov, L.G. Korshunov, A.G. Mukoseev, V.V. Sagaradze, A.V. Makarov, V.P. Pilyugin, S.I. Novikov, N.F. Vildanova, Mater. Sci. Eng. A 346, 196 (2003).

[16] A.G. Balanyuk, V.G. Gavriljuk, V.N. Shivanyuk, A.I. Tyshchenko, J.C. Rawers, Acta Mater. 48, 3813 (2000).

[17] E.J. Miola, S.D. De Souza, M. Olzon-Dionysio, D. Spinelli, C.A. Dos Santos, Surf. Coat. Technol. 116-119, 347 (1999).

[18] Y. Jirásková, J. Svoboda, O. Schneeweiss, W. Daves, F.D. Fischer, Appl. Surf. Sci. 239, 132 (2005).

[19] J. Krawczyk, P. Bała, A. Hanc, Archiv. Mater. Sci. Eng. 32, 45 (2008).

[20] J. Krawczyk, P. Bała, A. Hanc, Acta Phys. Pol. A 114, 1641 (2008). 